\title{
Kajian tekno-ekonomi produksi reaktor pirolisis dalam menghasilkan bioarang dan asap cair
}

\author{
Kemas Ridhuan ${ }^{1 *}$, Dwi Irawan², Yulita Zanaria ${ }^{3}$ \\ Prodi Teknik Mesin, Fakultas Teknik, Universitas Muhammadiyah Metro ${ }^{1,2}$ \\ Prodi Akuntansi, Fakultas Ekonomi, Universitas Muhammadiyah Metro ${ }^{3}$ \\ JI. Ki Hajar Dewantara 15 A Kota Metro, Lampung, Indonesia \\ Email:kmsridhuan69@gmail.com,dwi_irawan12@yahoo.co.id, yulitazanaria13@gmail.com
}

\begin{abstract}
The techno-economy of pyrolysis products is very important because it is related to the profit and loss of production business. On the other hand, this product is very potential and good prospect, due to it can generate energy from wasted and problematic environmental waste. In addition, the equipment is very simple and very easy to make, maintain and operate, it does not require a large cost or capital. The research objective is to determine the economic value and BEP (Break Even Point) of pyrolysis combustion in producing liquid smoke and bio charcoal with biomass raw materials. Figure the characteristics of liquid smoke and bio-charcoal obtained such as heat value, $\mathrm{pH}$, acid, specific gravity, viscosity, and color. The method used is initiated by testing the pyrolysis reactor, at this stage bio-charcoal products and liquid smoke are obtained, influenced by such as pyrolysis temperature, processing time and equipment. Followed by making bio charcoal briquette, this stage is mashed charcoal, making dough or packing, drying, then printing briquettes. And finally the process of re-liquidation of liquid smoke, by means of redestilation or continued heating so that it will produce liquid smoke grade 3, grade 2, and grade 1. The results obtained are known to have an economic cost of Rp. 244.720.000, and for equipment depreciation costs Rp. 144.839.000. For the cost of production per year, that is Rp. 100.925.000 and for the variable cost per $\mathrm{kg}$, which is $R p .4 .888 / \mathrm{kg}$. The initial capital required is Rp. 129.839.000. For the production cost of Rp. 7.476/kg. For the total price of sales is Rp. 100.939.306 and for BEP (Rp) which is Rp. 100.939.306 and BEP (kg) which is Rp. 13.495/kg.
\end{abstract}

Keywords: BEP, economy, pyrolysis, bio charcoal, liquid smoke.

\begin{abstract}
Abstrak
Tekno-ekonomi dari produ pirolisis sangat penting karena terkait untung dan rugi dari suatu usaha produksi. Disisi lain bahwa produk ini sangat potensial dan prospek yang baik sekali, karena bisa menghasilkan energi dari limbah lingkungan yang terbuang dan bermasalah. Selain itu peralatannya sangat sederhana dan mudah sekali dibuat dan dirawat serta mengoprasikannya, tidak memerlukan biaya atau modal yang besar. Tujuan penelitian mengetahui nilai ke-ekonomi dan BEP (Break Even Point) dari, Pembakaran pirolisis dalam menghasilkan asap cair dan bioarang dengan bahan baku biomasa. Mengetahui karaktristik hasil asap cair dan bioarang yang didapat seperti nilai kalor, $\mathrm{pH}$, asam, berat jenis, viskositas dan warnanya. Metode yang digunakan yaitu diawali dengan pengujian reaktor pirolisis, pada tahap ini didapat produk bioarang dan asap cair, dipengaruhi oleh seperti suhu pirolisis, waktu proses, dan peralatan. Dilanjutkan dengan pembuatan briket bioarang, tahap ini arang dihaluskan, pembuatan adonan atau pembriketan, pengeringan, lalu pencetakan briket. Dan terakhir proses redestilasi ulang asap cair, dengan cara redestilasi atau pemanasan lanjutan sehingga akan menghasilkan asap cair grade 3, grade 2, dan grade 1. Hasil yang didapat nilai ekonomi diketahui biaya investasi Rp.244.720.000, untuk biaya penyusutan peralatan Rp.144.839.000, untuk harga pokok produksi pertahun yaitu Rp.100.925.000, dan untuk
\end{abstract}


biaya biaya variabel per $\mathrm{kg}$ yaitu Rp. $4.888 / \mathrm{kg}$. Modal awal yang diperlukan yaitu Rp. 129.839.000, untuk harga pokok produksi Rp.7.476/kg. Untuk harga total penjualan ialah Rp. 100.939.306, dan untuk BEP (Rp) yaitu Rp. 100.939.306, dan BEP (kg) yaitu Rp.13.495/kg.

Kata kunci: BEP, ekonomi, Pirolisis, Bioarang, asap cair.

\section{Pendahuluan}

Isu energi dan lingkungan menjadi satu kesatuan penting yang tidak dapat diabaikan begitu saja karena saling berkaitan dan banyak menjadi pembicaraan publik untuk saat ini. Belakangan ditambah satu isu lagi yang cukup berkembang yaitu isu bahan kimia atau pengawet makanan yang banyak merugikan bagi kesehatan seperti formalin, borax dan lainnya.

Untuk menjawab isu-isu yang berkembang tesebut banyak hak yang dapat kita lakukan diantaranya yaitu penggunaa bahan biomassa pada reaktor pirolisis sebagai alat yang memproduksi berupa gas $(10-30 \%-w)$, cairan organik (40-65\%-w), dan padatan/char (10- 20\%w) menurut [1]. Dalam proses reaktor pirolisis didapat hasil produk berupa bioarang dan asap cair yang merupakan produk bahan bakar bernilai kalor tinggi, pupuk cair tanaman, bahan penggumpal latek dan bahan pengawet makanan. Menurut [2], asap cair mengandung senyawa kimia dan memiliki fungsi sebagai zat antimikroba dan cukup aman sebagai pengawet alam. Dengan pirolisis kita sudah melakukan konservasi energi dengan menghasilkan bioarang briket. Kemudian dengan pirolisis kita menggunakan limbah pertanian berati kita berupaya mencegah terjadinya pencemaran dan melestarikan lingkungan. Selanjutnya proses pirolisis menghasilkan asap cair yang merupakan bahan pengawet makanan, pupuk cair tanaman dan lainnya berarti kita sudah berupaya mencegah dan mengatasi kemungkinan penggunaan bahan pengawet kimia dan sejenisnya.

Pirolisis merupakan cara yang paling efektif untuk waktu saat ini karena dapat mengatasi tiga permasalahan sekaligus dengan satu usaha. Sehingga perlu disosialisasikan lebih luas lagi kepada penjuru masyarakat khususnya di pedesaan karena dapat meningkatkan perekonomian dan lapangan kerja masyarakatnya. Segmentasi pasar asap cair berdasarkan konsumen adalah industri pangan, industri pertanian dan industri perkebunan. Segmentasi pada industri pangan terdiri dari perusahaan buah-buahan, daging, tahu, ikan, dan bakso yang berguna sebagai pengawet. Pada industri pertanian adalah petani yang menggunakannya sebagai pestisida dan peternak yang menggunakannya untuk membersihkan kandang dan campuran pakan ternak. Pada industri perkebunan segmentasinya adalah perkebunan karet yang menggunakan asap cair sebagai koagulan lateks atau getah karet.

Ada beberapa dampak yang dapat ditimbulkan dari produk pirolisis ini seperti sebagai sentra energi daerah dan sentra usaha baru, meningkatkan lapangan pekerjaan, menghemat pengeluaran dan meningkatkan pendapatan keluarga dan lainnya. Terlihat bahwa prospek ekonomi dari produk pirolisis sangat baik sekali bagi perekonomian keluarga namun demikian perlu dikaji lebih dalam terkait dengan teknologi yang digunakan. Pembuatan bioarang dan asap cair dengan teknologi pirolisis ini belum banyak yang menggunakannya, padahal potensi bahan baku dan potensi pasar cukup menjanjikan. Dari aspek tenologi, pengolahan bioarang asap cair relatif masih sederhana dan dapat dilaksanakan oleh usaha-usaha skala kecil dan menengah. Keterbatasan modal, akses terhadap informasi pasar dan pasar yang terbata serta kualitas yang belum memenuhi persyaratan, merupakan kendala dan masalah dalam pengembangan usaha industri pengolahan bioarang asap cair. 
Teknologi yang digunakan untuk membuat asap cair yaitu pembakaran pirolisis dimana proses pemanasan biomassa di dalam reaktor dengan sedikit atau tanpa oksigen atau reagen lainnya yang menyebabkan biomassa mengalami pemecahan struktur kimia menjadi fase gas. Dalam fase gas tersebut terjadilah pemisahan bahan kimia berdasarkan perbedaan kecepatan atau kemudahan menguap dan kemudian gas tersebut di cairkan dikondensor dengan pendingin air sehingga terbentuklah asap cair. Di reaktor pembakaran menggunakan bahan bakar biomassa yang dibakar secara menyeluruh sekeliling reaktor, sehingga suhu pembakarannya tinggi dan waktu pirolisisnya singkat. Di kondensor menggunakan pipa bahan tembaga, agar pendinginan maksimal.

Untuk mengetahui lebih jauh prospeknya kiranya perlu dikaji teknoekonominya. Beberapa pertimbangan yang perlu untuk diketahui seperti penentuan harga pokok produk, modal, pengendalian biaya, biaya produksi, biaya pemasaran, biaya administrasi dan umum, tenaga kerja, peralatan, listrik, harga pokok produksi (HPP), dan break even point / BEP (aspek eknomi). dan yang lainnya. Dari produknya seperti kualitas biobriket yaitu nilai kalor, kadar air, kadar abu. Lalu pada asap cairnya ; kadar ph, asam asetat, lignin.

\section{Metode Penelitian}

Pelaksanaan penelitian ini terdiri dari beberapa tahap, yaitu:

1. Pengujian reaktor pirolisis, pada tahap ini bahan biomassa di dalam reaktor dipanasi oleh bahan bakar biomassa. Kualitas produk bioarang dan asap cair yang dihasilkan dipengaruhi oleh suhu, waktu proses dan peralatan (reaktor) serta biomassa yang digunakan. Menurut Ridhuan [3], jenis dan ukuran biomassa sangat mempengaruhi hasil pirolisis.

2. Pembuatan briket bioarang, tahap ini arang dihaluskan, kemudian dicampur dengan perekat lalu dibuat adonan setelah itu dicetak jadi briket lalu dikeringkan.

3. Proses lainnya yaitu asap cair, dimana asap cair yang telah didapat kemudian diredestilasi atau pemanasan lanjutan dan didestilasi ulang sehungga akan menghasilkan asap cair grade 2, kemudian diredestilasi akan menghasilkan grade 1 .

Bahan baku dan bahan bakar yang digunakan merupakan biomassa karena ingin memaksimalkan potensi sumber daya alam yang ada, dan biomassa yang digunakan yaitu kayu gelam, sekam padi dan cangkang karet, karena biomssa ini cukup baik (potensial), banyak dan mudah ditemukan disekitar lingkungan masyarakat.

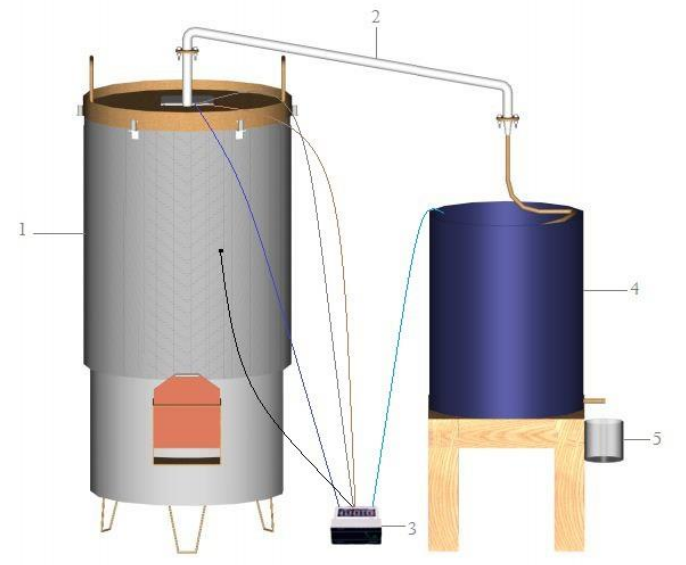

Gambar 1. Rangkaian sistem reaktor pirolisis dan kondensornya

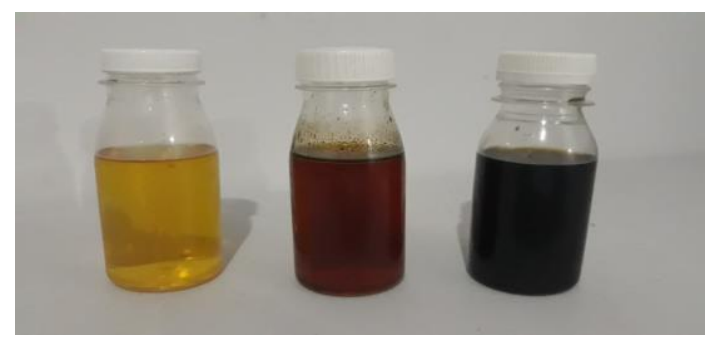

Gambar 2. Asap cair berbagai kualitas

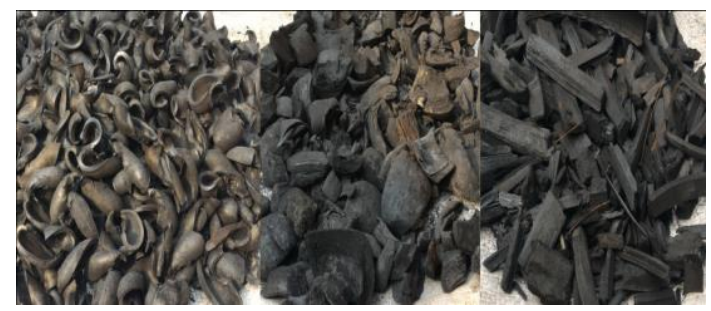

Gambar 3. Bioarang berbagai jenis 


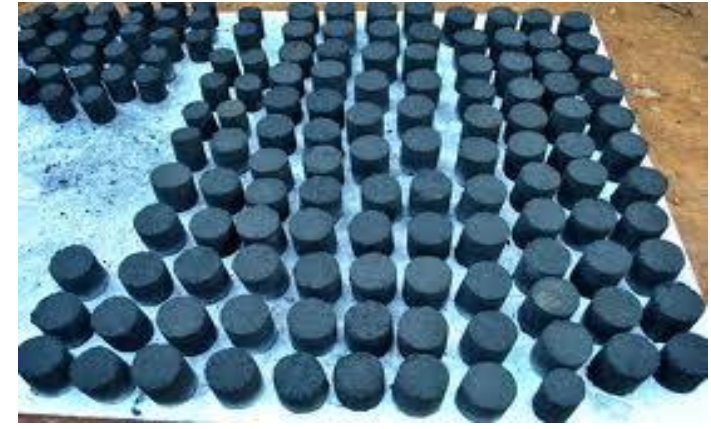

Gambar 4. Hasil briket bio-arang sekam

\section{Hasil dan Pembahasan}

Untuk mengetahui nilai keekonomian dari suatu kegiatan unit produksi maka harus diketahui beberapa jenis biaya, yaitu seperti:

1. Biaya investasi

Merupakan biaya yang diberikan oleh suatu pihak atau kelompok dengan tujuan untuk mendapatkan keuntungan dikemudian. Biaya investasi dikeluarkan pada awal tahun memulai usaha untuk membeli suatu investasi dan dikeluarkan lagi setelah umur ekonomisnya habis. Barang-barang yang menjadi investasi awal pada bisnis ini merupakan barang-barang yang diperlukan untuk memulai suatu kegiatan usaha. Biaya mesin dan alat produksi, biaya alat dan furnitur perkantoran, biaya bangunan dan infrastruktur [4]. Besaran biaya investasi tidak lebih dari 50 persen terhadap keseluruhan aset koperasi/usaha yang meliputi kepemilikan lahan dan sebagainya. Adapun biaya investasi yang dibutuhkan untuk mengawali usaha asap cair ini setelah ditambahkan dari beberapa biaya yaitu Rp. 244.720.000.

2. Biaya penyusutan

Biaya investasi yang dikeluarkan pada awal pendirian usaha akan mengalami penyusutan setiap tahun. Penyusutan tersebut dipengaruhi oleh umur ekonomis dari setiap barang investasi. Setelah umur ekonomis suatu barang telah habis maka harus dilakukan reinvestasi dengan biaya yang dikeluarkan pada tahun setelah pemakaian berakhir. Adapun total besarnya biaya penyusutan yaitu Rp.144.839.000.

3. Biaya Operasional

Yaitu biaya yang dikeluarkan untuk menjalankan operasional perusahaan terbagi dalam biaya tetap yaitu biaya yang tidak akan berubah beriringan dengan pertambahan kuantitas produk yang diproduksi dan biaya variabel yaitu biaya yang akan berubah mengikuti perubahan jumlah produksi terbagi 2 yaitu:

a) Biaya tetap Rp. 34.925.000.

b) Biaya variabel Rp. 66.000.000.

Maka, harga pokok produksi pertahun (HPPP) yaitu:

HPPP = Biaya tetap + Biaya variabel

$$
\begin{aligned}
& =34.925 .000+66.000 .000 \\
& =100.925 .000 \mathrm{rupiah} / \mathrm{tahun}
\end{aligned}
$$

Biaya variabel per kg:

$$
\begin{aligned}
\text { Bvkg } & =\frac{\text { Biaya variabel }}{\text { kapasitas produksi pertahun }} \\
& =\frac{66.000 .000}{13.500} \\
& =\text { Rp. } 4.888 / \mathrm{kg}
\end{aligned}
$$

Biaya tetap yang dikeluarkan dalam usaha ini adalah Rp 34.925.000 untuk tiap tahun. Biaya terbesar dalam komponen biaya tetap adalah biaya tenaga kerja tetap yaitu beban gaji bagi ketua, sekertaris, bendahara, bagian operasional, biaya kerjasama dan pemasaran serta tenaga kerja teknis. Modal awal merupakan biaya minimal yang dibutuhkan untuk memulai suatu bisnis. Modal awal ditentukan dari penjumlahan biaya investasi dan biaya operasional. Dalam usaha asap cair dan bioarang ini modal awal yang dibutuhkan yaitu sebesar Rp 129.839.000.

Biaya bahan baku langsung merupakan bahan yang secara menyeluruh membentuk produk selesai yang dapat diidentifikasikan secara langsung pada produk yang bersangkutan dan tidak dapat dipisahkan. Oleh karena itu biaya bahan baku ini dapat dibebankan secara langsung kepada produk karena pengamatan fisik dapat dilakukan untuk mengukur kuantitas 
(jumlah) yang dikomsumsi oleh setiap produk.

Reaktor pirolisis mimiliki kapasitas volume ruang pembakaran untuk biomassa kayu sebanyak $20 \mathrm{~kg}$, setelah pembakaran akan menghasilkan bioarang sebanyak 47 $\%$ dan asap cair $12 \%$ dalam satu kali produksi. Dalam satu hari bisa dilakukan 3 kali produksi dan satu bulan ada 25 hari kerja dan satu tahun ada 12 bulan.

Harga pokok produksi (HPP) menurut Bustami [5] adalah kumpulan biaya produksi yang terdiri dari bahan baku langsung, tenaga kerja langsung, dan biaya overhead pabrik ditambah persediaan produk dalam proses awal dan dikurang persediaan produk dalam proses akhir. Biaya ini diperoleh dengan menjumlahkan seluruh biaya yang dikeluarkan perusahaan selama satu tahun. Kapasitas produksi asap cair dan bioarang perhari adalah $45 \mathrm{~kg}$ dan kapasitas produksi pertahun adalah $13.500 \mathrm{~kg}$. Berikut data untuk menentukan harga pokok produksi yaitu:

$$
\begin{aligned}
\mathrm{HPP} & =\frac{\text { Harga pokok produksi pertahun }}{\text { Kapasitas produksi pertahun }} \\
& =\frac{100.925 .000}{13.500} \\
& =\text { Rp. } 7.476 / \mathrm{kg}
\end{aligned}
$$

Harga tersebut masih termasuk untuk kedua produk tersebut yaitu asap cair dan bioarang. Menurut Machmud [6], bahwa harga arang briket dalam negeri berkisar antara Rp. 2000 sampai Rp. 2500 perkilogram, sedangkan harga ekspor berkisar antara Rp. 6000 sampai Rp. 8000 perkilogram. Sementara itu Andayani [7], mengatakan bahwa Harga Pokok Produksi (HPP) dari produk karbon aktif dengan asap cair adalah Rp. 191.502/unit dan Rp. 63.834/botol, harga jual di tingkat produsen hingga pengecer adalah $\mathrm{Rp}$. 268.103/unit atau Rp. 13.406/kg dan Rp. 89.368/botol dengan asumsi pengambilan keuntungan (mark up) sebesar $40 \%$ dari harga pokok produksi.
Ini menunjukkan bahwa hasil perhitungan yang dilakukan masih dalam nilai yang wajar dan standar jika dibandingkan dengan hasil penelitian sebelumnya yang telah dilakukan. Harga jual tersebut masih bisa dinaikkan lagi margin-nya untuk mendapatkan keuntungan yang wajar.

Harga total penjualan (HTP), didapat dari kapasitas produksi per tahun $(\mathrm{Kp})$ yang dihasilkan dikalikan dengan harga jual per $\mathrm{kg}$, atau sama dengan nilai harga pokok produksi pertahun, yaitu:

$$
\begin{aligned}
\text { HTP } & =13.500 \times 7.476 \\
& =\text { Rp. } 100.925 .000
\end{aligned}
$$

Break Even Point (BEP) adalah suatu keadaan di mana dalam operasi perusahaan, perusahaan itu tidak memperoleh laba dan tidak menderita rugi. Titik pulang pokok atau BEP proyek merupakan jumlah unit yang harus dijual atau nilai minimal yang harus diperoleh dari sebuah usaha bisnis agar dapat mengembalikan semua investasi yang dikeluarkan.

Break even point produksi dari pirolisis biomassa ini adalah:

$$
\begin{aligned}
\operatorname{BEP}(\mathrm{kg})=\frac{\text { Biaya tetap }}{\text { Harga jual } / \mathrm{kg}-\text { Biaya variabel } / \mathrm{kg}} \\
=\frac{34.925 .000}{7.476-4.888} \\
=\text { Rp. } 13.495 / \mathrm{kg}
\end{aligned}
$$

Break even point harga dari pirolisis biomassa ini adalah:

$$
\begin{aligned}
\operatorname{BEP}(\mathrm{Rp}) & =\frac{\text { Biaya tetap }}{1-\frac{\text { Biaya variabel }}{\text { Total penjualan }}} \\
& =\frac{34.925 .000}{1-\frac{66.000 .000}{100.925 .000}} \\
& =\text { Rp. } 100.939 .306
\end{aligned}
$$

Berdasarkan perhitungan di atas, nilai BEP untuk usaha asap cair ini adalah sebesar Rp. 100.939.306, hal tersebut menunjukkan bahwa agar usaha asap cair berada pada titik impas, maka jumlah penerimaan minimal pertahunnya sebesar Rp. 100.939.306. Apabila penerimaan kurang dari nilai BEP harga tersebut, maka 
usaha dikatakan rugi, dan apabila penerimaan lebih dari nilai BEP harga maka usaha memperoleh keuntungan. Hasil ini masih cukup kecil jika diabandingkan dengan penelitian Ariyanti [8] bahwa Break Event Point (BEP) dicapai pada volume penjualan 871 unit atau senilai Rp. 233.436.408 untuk produk karbon aktif dan volume penjualan 2.613 unit atau senilai Rp. 233.436.408 untuk produk asap cair biomassa.

Titik balik modal (BEP) dalam satuan $\mathrm{kg}$ adalah sebesar Rp. 13.495/kg dan dalam rupiah sebesar Rp. 100.939.306. Dengan asumsi_jumlah penjualan sama dalam 1 hari selama 1 tahun. Sedangkan payback priod untuk investasi usaha briket bioarang ini adalah selama 90 hari. Briket organik terbuat dari limbah yang mudah diperoleh, tersedia dalam jumlah yang banyak dan harga yang sangat murah atau malah pada beberapa tempat sampah tertentu bisa diperoleh secara gratis, serta pembuatannyapun relatif mudah.

Untuk melihat efisiensi dan penghematan bahan bakar, dapat juga dilakukan dengan membandingkan nilai kalor persatuan rupiahnya. Adapun hasil perbandingan nilai ekonomi menurut Mulyanti [9] bahwa dari data perbandingan efisiensi bahan bakar, dapat dilihat bahwa perkilo kalori briket bioarang dari biomassa ini jauh lebih murah jika dibandingkan harga minyak tanah dan gas LPG. Jika suatu rumah tangga membutuhkan minyak tanah sebanyak 4 liter perhari, dimana nilai kalori minyak tanah adalah $11.000 \mathrm{kal}$, maka kebutuhan energi rumah tangga terhadap minyak tanah adalah 44.000 $\mathrm{kal} /$ hari. Jika harga minyak tanah saat ini adalah Rp 8.500,00 maka satu keluarga membutuhkan biaya energi sebesar $\mathrm{Rp}$ $34.000,00$ per hari. Nilai kebutuhan energi minyak tanah ini dijadikan sebagai dasar perbandingan kebutuhan kebutuhan kalori dari dua bahan bakar yang berbeda yakni LPG dan briket arang ini. Untuk memenuhi kebutuhan energi rumah tangga sebesar $44.000 \mathrm{kal} / \mathrm{hari}$ dengan menggunakan LPG diperoleh biaya konsumsi energi sebesar Rp. 27.194,96. Sedangkan dengan menggunakan briket arang ini, biaya konsumsi energi untuk memenuhi kebutuhan energi rumah tangga sebesar 44.000 kal hanya dibutuhkan biaya Rp. 26.647,02. Dari hasil perbandingan biaya konsumsi energi ini, terlihat jelas efisiensi yang dihasilkan jika menggunakan briket arang ini. Selain untuk mengurangi ketergantungan terhadap bahan bakar fosil yang unrenewable dan unsustainable, pemanfaatan briket bioarang ini juga dapat mejadi alternatif energi murah, terutama untuk kalangan ekonomi menengah ke bawah.

\section{Kesimpulan}

Untuk nilai keekonomian diketahui biaya investasi Rp. 244.720.000, dan untuk biaya penyusutan peralatan Rp. 144.839.000. Untuk harga pokok produksi pertahun yaitu Rp.100.925.000 dan untuk biaya variabel per kg yaitu Rp. $4.888 / \mathrm{kg}$. Modal awal yang diperlukan yaitu Rp. 129.839.000 untuk harga pokok produksi Rp. $7.476 / \mathrm{kg}$. Untuk harga total penjualan ialah Rp. 100.939.306 dan untuk BEP (Rp) yaitu Rp. 100.939.306 dan BEP (kg) yaitu Rp. $13.495 / \mathrm{kg}$.

Karakteristik asap cair yang dihasilkan yaitu kadar $\mathrm{pH}$ berkisar 2,6 s.d. 2,9 . Untuk warna asap cair yang menggunakan zeolite berwarna kuning dan yang tidak berwarna hitam pekat. Dan untuk karaktristik bioarang yaitu kadar abu berkisar 51,19 s.d. 56,31, kadar air 3,1\% dan nilai kalor $8.278,01$ s.d. $9.389,39$ $\mathrm{kal} / \mathrm{kg}$.

\section{Saran}

Untuk mendapatkan hasil yang lebih baik dapat menggunakan bahan bakar biomassa yang berbentuk bongkahan sedang karena pembakaran akan berlangsung kontinyu. Dan cara pembakarannya dengan sekeliling dinding 
reaktor dan ini akan mempercepat waktu pembakaran.

Untuk mendapatkan hasil asap cair yang lebih bersih dapat meneliti dengan menggunakan zeolit yang berfungsi sebagai filter agar dapat menyerap tar lebih baik lagi sehingga asap cair yang dihasilkan dapat lebih bersih lagi.

Untuk mendapatkan hasil asap cair yang lebih efektif, dan tidak perlu menguji dengan redistilasi maka perlu dilakukan penelitian mengenai pirolisis bertingkat, dengan satu kali pengujian maka hasil asap cair dapat langsung diperoleh dengan kualitas lebih bersih.

\section{Ucapan Terima Kasih}

Ucapan terima kasih disampaikan kepada Direktorat Riset dan Pengabdian Masyarakat Kementrian Riset Teknologi dan Pendidikan Tinggi Republik Indonesia yang sudah mendukung penelitian ini dalam program Penelitian Strategis Nasional Nomor: 224/SP2H/RT/DRPM2019. Dan tidak lupa pula kepada Rektor Universitas Muhammadiyah Metro serta Ketua Lembaga Penelitian dan Pengabdian kepada Masyarakat Universitas Muhammadiyah Metro.

\section{Referensi}

[1]. Iskandar, Taufik,. Chandra Kartika Fitri, Ayu,. 2018,. Asap Cair dan Biochar hasil Proses Pyrolisis Sekam Padi dan Biomassa lainnya sebagai Income Generating Unit di Universitas Tribhuwana Tunggadewi, JAST: Jurnal Aplikasi Sains dan Teknologi, 2 (2), Halaman: 81 - $87 \quad$ online https://jurnal.unitri.ac.id/index.php/ja st. ISSN 2548-7981 (Online).

[2]. Wastono. 2006. Kajian sistem produksi destilat asap tempurung kelapa dan aplikasinya sebagai disinfektan untuk memperpanjang masa simpan buah pisang. Institut Pertanian Bogor. Bogor. Universitas.
[3]. Ridhuan, Kemas,. Irawan, Dwi,. Setiawan, Rahmady, 2019, Comparison Of Types And Size Of Biomass On Pirolysis Combustion Toward The Results Of BioCharcoal And Liquid Smoke, The 5TH International Conference on Science, Technology and Interdisciplinary Research, ICSTAR, di Hotel Emersias, Bandar Lampung, Indonesia.

[4]. Machrush, Cania, Putra, Muhammad,. 2015, Perencanaan Bisnis Asap Cair Tempurung Kelapa Melalui Pendekatan Wirakoperasi Di Kabupaten Bogor, Departemen Agribisnis Fakultas Ekonomi Dan Manajemen Institut Pertanian Bogor Bogor.

[5]. Bustami, Bastian,. Nurlela, 2010. Akuntansi Biaya, Edisi Kedua, Penerbit Mitra Wacana Media, Jakarta.

[6]. Machmud, Senen, 2011, Kajian Ekonomis Industri Briket Arang Tempurung Kelapa, Jurnal Ekonomi, Bisnis \& Entrepreneurship Vol. 5, No. 1, Hal.: 45-51, ISSN 24430633.

[7]. Andayani, Wati,. 2014, Penentuan Harga Pokok Produksi Lele Pada Petani Lele Di Kecamatan Sukowono Kabupaten Jember, Skripsi, Jurusan Akuntansi Fakultas Ekonomi Universitas Jember.

[8]. Ariyanti, Retno,. Mangesti Rahayu, Sri, 2014, Analisis Break Even Point Sebagai Dasar Pengambilan Keputusan Manajemen Terhadap Perencanaan Volume Penjualan Dan Laba, Jurnal Administrasi Bisnis (JAB) Vol. 11 No. 1.

[9]. Mulyati, Meylinda,. 2016, Analisis Tekno Ekonomi Briket Arang Dari Sampah Daun Kering, Jurnal Teknoin, Vol. 22 No 7, Hal: 505513. 